Relations industrielles

Industrial Relations

\title{
Les nouvelles formes d'organisation du travail, vol. 2, Genève, Bureau international du travail, 1979, 161 pp.
}

\section{Alain Vinet}

Volume 35, numéro 2, 1980

URI : https://id.erudit.org/iderudit/029078ar

DOI : https://doi.org/10.7202/029078ar

Aller au sommaire du numéro

Éditeur(s)

Département des relations industrielles de l'Université Laval

ISSN

0034-379X (imprimé)

1703-8138 (numérique)

Découvrir la revue

Citer ce compte rendu

Vinet, A. (1980). Compte rendu de [Les nouvelles formes d'organisation du travail, vol. 2, Genève, Bureau international du travail, 1979, 161 pp.] Relations industrielles / Industrial Relations, 35(2), 350-350.

https://doi.org/10.7202/029078ar

Tous droits réservés (C) Département des relations industrielles de l'Université Laval, 1980
Ce document est protégé par la loi sur le droit d'auteur. L'utilisation des services d'Érudit (y compris la reproduction) est assujettie à sa politique d'utilisation que vous pouvez consulter en ligne.

https://apropos.erudit.org/fr/usagers/politique-dutilisation/ 
tiens pour un livre de référence, particulièrement en Europe latine, sur la médiation des pouvoirs publics dans les conflits collectifs du travail: La mediazione dei publici poteri nei conflitti collettive di lavoro (Bologna, Il Mulino, 1972). L'auteur, Bruno Veneziani, dont j'ai déjà eu l'occasion de parler dans ces colonnes à propos de deux autres volumes collectifs parus en 1978 (voir Relations industrielles, vol. 34, no. 1, 1979, pp. 205-206), est également le signataire d'une contribution sur le même sujet au 26e volume de l'Encyclopédie du Droit: "Mediazione nelle controversie collettive di laboro" (Enciclopedia del diritto, Milano, Giuffrè Editore, 1976).

\section{Dimitri WEISS}

Institut d'Administration des Entreprises, Paris

Les nouvelles formes d'organisation du travail, vol. 2, Genève, Bureau international du travail, 1979, $161 \mathrm{pp}$.

Dans un premier volume (Les nouvelles formes d'organisation du travail, 1979), le Bureau international du travail a déjà publié cinq monographies sur les nouvelles formes d'organisation du travail au Danemark, en Norvège et en Suède, en République fédérale d'Allemagne, en France, au Royaume-Uni et aux États-Unis. Dans ce deuxième volume, le BIT s'intéresse à des expériences tentées en Italie, en Inde, en République démocratique allemande et en URSS.

Bien que l'avant-propos comprenne un avertissement concernant le caractère disparate des analyses regroupées dans ce second volume, le lecteur est néanmoins assuré d'y trouver une trame, un commun dénominateur. En effet, tous les auteurs manifestent d'une façon ou d'une autre une préoccupation envers des considérations théoriques: fondements des systèmes d'organisation du travail, évolution du marché de l'emploi, répercussions du progrès technique, principes d'organisation etc. De plus, pour chaque pays, on s'attarde à décrire le système d'organisation du travail en vigueur ainsi que la démarche jugée la plus appropriée pour con- tribuer à son amélioration. Enfin, dans tous les cas, des exemples concrets sont présentés.

Mais là s'arrêtent les points communs. Certaines monographies ont été rédigées par des chercheurs indépendants tandis que d'autres l'ont été par des spécialistes à l'emploi d'organismes of ficiels. Les opinions émises à l'égard de l'organisation du travail varient largement et se situent de façon différente par rapport au système socio-économique des pays concernés. En regroupant ces monographies, l'objectif du BIT n'était pas de prendre position sur les opinions exprimées mais de montrer «comment les chercheurs ou les spécialistes des organismes of ficiels envisagent le problème dans différents pays». Au lecteur de juger. Le choix des expériences est varié et comprend aussi bien des groupes semi-autonomes dans la métallurgie italienne que l'application du système scientifique d'organisation du travail dans l'industrie textile soviétique.

Cette publication du BIT comprend également un article de Anthony Hopwood consacré à l'évaluation de l'intérêt économique des nouvelles formes d'organisation du travail. À la suite de son analyse, l'auteur conclut que les normes visant à améliorer la qualité de la vie au travail, bien qu'elles soient parfois coûteuses, «peuvent avoir une incidence positive sur les résultats économiques généraux des entreprises». À partir d'exemples, il discute des facteurs agissant sur les résultats économiques des mesures d'amélioration de la qualité de la vie au travail. Cependant, ce type d'évaluation n'est pas sans poser de délicats problèmes de mesure au point d'exiger souvent une remise en cause de la façon traditionnelle d'envisager les performances et les résultats de l'entreprise.

Alain VINET

Université Laval

Administration industrielle et générale, par Henri Fayol, édition présentée par P. Morin, Paris, Dunod, 1979, 156 pp.

Les spécialistes et observateurs des relations industrielles sont familiarisés avec ce 